\title{
Against Storytelling-The New Paradigm of Scientific Publishing
}

\author{
Anne-Katharina Weilenmann $1, *(1)$ and Lawrence Rajendran ${ }^{2}$ \\ 1 Library and Information Management, Stettemerstrasse 165, CH-8207 Schaffhausen, Switzerland \\ 2 Institute for Regenerative Medicine-IREM, University of Zurich Campus Schlieren, Wagistrasse 12, \\ CH-8952 Schlieren, Switzerland; lawrence.rajendran@irem.uzh.ch \\ * Correspondence: weilenmann@shinternet.ch
}

Received: 30 October 2018; Accepted: 19 November 2018; Published: 22 November 2018

This is an interview which I conducted with Lawrence Rajendran, the founder and initiator of the platform «ScienceMatters». [1]

Anne-Katharina Weilenmann (AKW): Why did you initiate and found the platform "ScienceMatters" and what is the scope of it?

Lawrence Rajendran (LR): The need to publish "sexy" scientific stories has become more important than a solid, standalone observation in many fields. Plus, the science publishing system exerts enormous pressure on scientists to turn simple-sometimes powerful-observations into flashy stories, and since universities and funding agencies judge researchers on their publishing record, we have no choice but to oblige. Storytelling has thus become the prevailing paradigm of scientific publishing.

But this emphasis on storytelling is accompanied by further problems such as delayed reporting of major observations, non-reporting of 'inconvenient' facts and orphan observations, and a strong publication bias. These systemic flaws partly contribute to the alarming increase of irreproducible results, retractions of papers and fake studies, and studies reviewed by fake reviewers.

ScienceMatters eliminates the need to spin big stories from simple observations as there is no pressure to create stories, no reason to delay publication and no reason to omit 'inconvenient truths'. The advantages of this single-observation publishing are myriad: It eliminates the need for scientists to delay disclosing their results while they collect months or years' worth of additional data in pursuit of a long, drawn-out story. It also allows scientists to publish those intriguing observations that might otherwise lie forever unpublished, whether for lack of resources or because they cannot currently be explained [2].

AKW: Where do you see the greatest challenges in scientific publishing today?

LR: I see the greatest challenges in these three aspects:

1. Barriers to create knowledge: demands to tell bigger and sensational stories and that journals impose artificial thresholds as to what can constitute a publication. Because of this, long delays in getting from the author's work, be it hypothesis or observations or research data, to publication. During this long delay where the authors' knowledge is hidden and unshared, this makes science closed.

2. Barriers to access knowledge: paywalled articles still exist. I think in 2018, to have knowledge created by public funds, behind paywalls is morally irresponsible, in my opinion.

3. Reluctance to embrace digital technologies to improve science publishing: Academia is unusually slow to adopt technologies to make science publishing efficient. We were one of the last ones to adopt digital technologies-we still use archaic methods such as writing in MS-Word, make PDFs, send it around to reviewers who in turn send in their reviews through a word document or authors 
make their revisions using word documents which then go several rounds of copy-editing-which are some of the most inefficient ways of publishing. Similarly, demand to tell stories and submit story-based narratives during the initial submission already makes the whole process inefficient-modular publishing as we practice in ScienceMatters, could make the whole process much more efficient. ScienceMatters tries to leverage advanced digital technologies including blockchain technology to make the whole publishing process efficient.

AKW: The Association of Scientific and Medical Publishers (STM) has published the Techtrends for the year 2021 [3]. Artificial intelligence (AI) and blockchain are important issues. To your mind, how will AI influence the scientific knowledge cycle and scholarly communication process?

LR: Interesting that you mention AI and blockchain-both of which we, at ScienceMatters, are trying to implement and leverage in publishing. In my opinion, there is much more data that we produce than we can assimilate. Not just the abundance of big data, almost every other instrument used in experimental research gives abundant of data as output. We scientists take data that we deem the most relevant and process for further studies/publication. How about the whole data that is hidden in supplementary data to data usually never sees the daylight in terms of scholarly space. AI could help here-both in terms of making sense of data and also in peer-review. However, just AI would not be the solution, at least not now. My recommendation is a constant man-machine interaction to both the parties - both peer-review process done by humans as well as AI's capacity to peer-review. Blockchain, on the other hand, is the technology that we absolutely need in publishing-blockchain removes the need for overreliance of trust on some middlemen (typically publishers in this industry) and also on authors by enabling peer to peer transaction of research value. Blockchain technology allows timestamping discoveries to decentralized publishing. Smart contracts can allow payments from authors or to reviewers thereby making the publishing landscape not only more efficient but also fairer to all the stakeholders involved.

AKW: Kevin Kelly (Wired-Editor) stated: "In the new world of books, every bit informs another; every page reads all the other pages [4]." What do you think about?

LR: I read this when it came out almost a decade ago and I think it holds water even today and perhaps also for the future. In the world of ever-increasing connectedness and the desire to assimilate as much information as possible, I do think this is absolutely true. And indeed we have become increasingly efficient in assimilating information. What I am not sure is if we have evolved to transform information to knowledge and knowledge to wisdom. Recent study seems to suggest that we have not [5].

The study by Vosoughi et al. suggests that humans spread fake news faster than true news-which is truly disturbing. The fact that diffusivity of falsehood is significantly faster and more penetrating is awfully scary.

AKW: Creating and disseminating new knowledge are essential parts of the scientific landscape. Do you have any ideas how the scientific and scholarly ecosystem could look like in the year 2030?

LR: I think (and secretly hope) that there is some kind of retrograde evolution here- that we stop being such overactive hamsters on ever-faster turning wheels churning out more and more data but we slow down, take our time to convert data into wisdom-with the help of AI.

I do not see existence of publishers at all in 2030, instead, I see peer to peer transactions of research and scholarly work happening through advanced blockchain-based operations (remember the evolution of the Internet over the last 20 years).

I see a fairer landscape where the world looks better (I know that given the current geopolitical climate, this may sound far-fetched, but I am optimistic that technology and wisdom will allow us to make the world a fairer, better place). I have prodigious hope on our younger generation.

AKW: Mr. Rajendran, I thank you very much for the interview and your time.

LR: Thank you! 
Author Contributions: Author: A.-K.W.; Interviewee: L.R.

Funding: This research received no external funding.

Conflicts of Interest: The authors declare no conflict of interest.

\section{References}

1. ScienceMatters. Available online: http://www.sciencematters.io (accessed on 4 August 2018).

2. The First Answer Is the Same as the Answer I Gave during an Interview. Available online: https: / retractionwatch.com/2016/06/27/publishing-needs-more-science-fewer-stories-qa-withfounders-of-sciencematters/ (accessed on 4 August 2018).

3. Smit, E. STM Tech Trends 2021: Trust and Integrity. In Proceedings of the STM Annual US Conference, Washington, DC, USA, 25-27 April 2017; Available online: https:/ / tinyurl.com/y8rnfcq8 (accessed on 4 August 2018).

4. Kelly, K. Scan this Book! In The New York Times; Routledge: New York, NY, USA; London, UK, 2006; Available online: http:/ / www.nytimes.com/2006/05/14/magazine/14publishing.html (accessed on 4 August 2018).

5. Vosoughi, S.; Roy, D.; Aral, S. The spread of true and false news online. Science 2018, 359, $1146-1151$. [CrossRef] [PubMed]

(C) 2018 by the authors. Licensee MDPI, Basel, Switzerland. This article is an open access article distributed under the terms and conditions of the Creative Commons Attribution (CC BY) license (http://creativecommons.org/licenses/by/4.0/). 